\title{
Uma Análise Econômico-Atuarial dos Death Bonds*
}

\author{
João Vinícius de França Carvalho ${ }^{\dagger}$, Luís Eduardo Afonso ${ }^{\ddagger}$
}

\author{
Contents: 1. Introdução; 2. Revisão da Literatura; 3. O Produto Financeiro Death Bond; \\ 4. Metodologia; 5. Simulações; 6. Seleção Adversa: Tentando Identificar o \\ Segurado Mais Lucrativo; 7. Considerações Finais. \\ Keywords: Death Bonds; Seguro de Vida; Modelos Atuariais; Mercado Secundário. \\ JEL Code: G22; J17; D40.
}

Um death bond é um título emitido por uma instituição financeira para comprar uma apólice de seguro de vida de um segurado que deseja receber recursos ainda em vida. Este trabalho faz a precificação dos death bonds para ambos os gêneros e diferentes idades de contratação do seguro, empregando técnicas de modelagem atuarial. Os resultados iniciais mostram pouca atratividade para os investidores no título. Uma extensão do modelo mostra que se os investidores conseguirem identificar os segurados com as piores condições de saúde, os retornos são substancialmente mais elevados e os desvios-padrão são bastante reduzidos.

A death bond is issued by a financial institution to buy a life insurance policy from an insured who wishes to receive funds during his lifetime. This work presents the pricing of death bonds for both genders and different ages of the initial contract, using actuarial modeling techniques. Initial results show little attraction for the bonds' investors. An extension of the model shows that if investors can identify the individuals with the worst health conditions, the returns are substantially higher and the standard deviations are quite low.

\section{INTRODUÇÃO}

O seguro de vida é um produto concebido sob a premissa de altruísmo do contratante. $O$ valor do benefício está relacionado à segurança financeira e ao conforto que o pagamento do benefício pode

\footnotetext{
* Os autores agradecem ao parecerista anônimo pelos pertinentes comentários efetuados quando de uma versão anterior deste trabalho. Não obstante, todos os eventuais erros são de nossa inteira responsabilidade.

$\dagger$ Escola Superior de Administração e Gestão. E-mail: jvf carvalho@gmail .com

¥Departamento de Contabilidade e Atuária - FEA-USP. Endereço para correspondência: Universidade de São Paulo, Faculdade de Economia Administração e Contabilidade, Departamento de Contabilidade e Atuária. Av. Prof. Luciano Gualberto, 908. FEA 3 , Sala 107, Butantã, 05508-010 - São Paulo, SP - Brasil. E-mail: lafonso@usp.br
} 
proporcionar aos dependentes do segurado falecido. Tradicionalmente, o seguro de vida tem sido tratado como um ativo ilíquido, por não existir um mercado secundário em que seja possível a venda de apólices. Por este motivo, as únicas opções do segurado eram manter a apólice até o fim da vida ou devolvê-la para a seguradora por um valor fixado previamente. Nesta segunda situação, o objetivo de manter o valor proporcional ao tempo de contrato poderia não ser plenamente cumprido, uma vez que a entidade seguradora penalizaria de modo exagerado o portador, devido a custos diversos como taxas de administração, subscrição, prêmios de resseguros ou comissões, impondo-lhe elevado deságio pelo resgate antecipado dos recursos acumulados.

No entanto, devido a motivos diversos, como problemas de saúde, necessidade de recursos ou mudança nas preferências, poderia ser de interesse do segurado tornar líquidos, ainda em vida, os recursos que só seriam pagos após a ocorrência de sua morte. Caso esta alternativa fosse viável, o segurado ofertaria sua apólice no mercado financeiro, para que algum agente ofertasse um valor mais elevado do que o proposto pela seguradora, obtendo desta forma uma taxa de retorno mais alta do que aquela obtida na transação com a seguradora. Nos últimos anos, o entendimento sobre as possibilidades financeiras de um seguro de vida tem mudado de modo considerável. Em países como a Alemanha e o Reino Unido, alguns segurados têm negociado suas apólices no mercado secundário. Havendo a efetivação de contrato entre o segurado e a instituição do mercado financeiro, o título recebe a denominação de death bond. Embora seja, a partir deste instante, um título financeiro, o problema de precificação da apólice no mercado secundário tem características atuariais, visto que o pagamento do benefício é certo, porém com o tempo de execução incerto, sendo a tábua de mortalidade o principal fator de decrescimento para a taxa de retorno do portador do título de vida.

Para o segurado, o ganho nesta transação está relacionado ao recebimento antecipado dos recursos, com deságio menor do que a seguradora lhe pagaria. Por um lado este novo mercado pode ser uma alternativa à rigidez imposta pela seguradora em sua relação contratual com o segurado, aumentando o bem-estar deste último. Por outro lado, neste novo mercado pode existir um conjunto particular de imperfeições. Há possibilidade de seleção adversa, atraindo para negociar suas apólices os indivíduos menos desejados pelo demandante. ${ }^{1}$ Para o comprador da apólice, o ganho é inversamente proporcional ao tempo de sobrevivência do vendedor. Esta característica pode criar incentivos perversos pelo desejo da morte precoce do antigo segurado, o que aumentaria o lucro das firmas adquirentes de seguros de vida. Estes incentivos são a razão principal pela qual o tema tornou-se polêmico. ${ }^{2}$ Portanto, dadas as falhas existentes, para o bom funcionamento deste mercado, é necessário que haja a devida regulamentação e existam mecanismos para reduzir eventuais comportamentos indesejados das partes envolvidas.

Tendo com base o quadro descrito, o objetivo do presente trabalho consiste em analisar a viabilidade deste mercado, por meio de simulações desde a precificação da seguradora pelo contrato até o apreçamento desses títulos pelo mercado secundário. Além disso, ao avaliar os impactos das possíveis falhas existentes neste mercado, o trabalho identifica não só o público-alvo do novo produto que tornam maiores os ganhos dos investidores, como também quantifica os possíveis retornos financeiros para diversos cenários.

O trabalho está dividido em mais cinco seções, além desta Introdução. Na seção seguinte é feita uma revisão da literatura sobre o tema. Na terceira seção são apresentadas as características de funcionamento do mercado secundário. Na quarta seção são definidas as notações, terminologias e as metodologias empregadas. A Seção 5 traz os resultados obtidos por meio das simulações. A Seção

\footnotetext{
${ }^{1}$ Note-se que neste caso, o cliente menos desejado pode ser aquele com maior expectativa de vida.

${ }^{2}$ Algumas publicações nacionais e internacionais da imprensa deram atenção especial ao tema: a edição de 30/jul/2007 da revista BusinessWeek, a edição de 10/mar/2010 do diário The Wall Street Journal e, no Brasil, um artigo na edição 271 (nov/2009) da revista Superinteressante. Já na internet, surgiram diversas manifestações repudiando a existência deste mercado, sendo o mais expressivo o sítio www. nodeathbonds.com.
} 
6 apresenta resultados considerando uma falha de mercado, e, finalizando, na Seção 7 são feitas as considerações finais.

\section{REVISÃO DA LITERATURA}

Há diversas publicações jornalísticas, porém poucos artigos sobre os death bonds. Um destes artigos acadêmicos é de Quinn (2008) que, abordando implicações morais importantes, faz um levantamento de notícias e entrevistas para descrever três concepções deste mercado: sacred revulsion, consumerist consolation, e rationalized reconciliation. O primeiro conceito, de forma bastante original, santifica as apólices de seguro de vida, vidas e mortes que os contratos representam, de forma que estas sejam adequadas de serem protegidas por meio do mercado. O segundo termo, segundo o autor, faz menção aos altos custos associados à morte de uma pessoa, justificando as negociações como o financiamento de uma morte digna e confortável. Por fim, o último elemento explica que o anonimato e a distância dos compradores e do antigo segurado eliminam todo e qualquer dilema moral: a venda das apólices contratadas é classificada como moral, por ser vista como um empreendimento puramente racional, impessoal e passível de precificação.

Gatzert (2010) identifica características e implicações econômicas do mercado secundário para seguros de vida, comparando os mercados do Reino Unido, Alemanha (em ambos, o ativo é tratado como um título de renda fixa) e EUA (cuja predominância é negociar seguros de vida de idosos com expectativa de vida reduzida). A autora argumenta que o principal fator para o sucesso do mercado secundário é o tamanho do mercado primário: com muitas apólices emitidas, haveria maiores possibilidades de negociação. Doherty and Singer (2002) avaliam que o desenvolvimento do mercado secundário poderia provocar um aumento na demanda por seguro de vida, trazendo benefícios para os ofertantes do mercado segurador primário à medida que tal aumento reduziria o risco de liquidez das seguradoras. Por outro lado, poderia haver aumento significativo no valor de prêmios para os segurados, uma vez que um mercado secundário eficiente aumenta a liquidez do título, tornando o seguro de vida um bem de valor maior para os consumidores. Tal aumento do valor, supondo tudo o mais constante, aumentaria a demanda por seguros de vida, resultando em um valor de mercado mais alto.

O lado da demanda também é lembrado por Gatzert (2010), pois os investidores exigirão uma compensação adequada por investirem neste produto, além de haver desenvolvimento deste mercado devido a melhorias em métodos de precificação. Neste contexto, taxas de juros mais baixas levarão a uma diversificação de seus portfólios, gerando uma procura maior por títulos lastreados em seguros de vida.

Focando sua atenção no segurado, Doherty and Singer (2002) demonstram que o surgimento de um mercado secundário faz com que haja ganhos de bem-estar, em particular para aqueles que necessitem de liquidez por qualquer razão. Eles alertam para o fato de que o segurado, por ter um papel ativo na decisão de venda de seu título, precisa estar bem informado sobre todas as possibilidades de mudanças de regime da apólice original, como, por exemplo, a opção do seguro quitado (em caso de eventual falta de pagamento, como será abordado na subseção 4.1), entre outras opções, para que não tenha prejuízos inesperados.

A relação contratual entre as partes possui implicações jurídicas para um mercado secundário, discutidas por Gatzert (2010), as quais versam sobre a questão do interesse segurável ${ }^{3}$ entre segurado, segurador e beneficiário. O autor cita um entendimento da Corte britânica datado de 1854 que determinou que o interesse segurável deve estar presente no momento da emissão, mas não nos períodos subseqüentes. Já nos EUA, o entendimento de que os títulos provêm de pessoas desconhecidas dos investidores é considerado problemático por seguradores e associações populares, devido ao fato

\footnotetext{
${ }^{3}$ De acordo com o Art. 757 do Código Civil Brasileiro (2002), "Pelo contrato de seguro, o segurador se obriga, mediante o pagamento do prêmio, a garantir interesse legítimo do segurado, relativo a pessoa ou a coisa, contra riscos predeterminados". Assim, entende-se por interesse segurável um objeto do contrato de seguro, passível de sinistro.
} 
de que os contratos são adquiridos sem interesse segurável legítimo, iniciados e controlados por investidores, cuja única intenção é revendê-los em mercado secundário.

Na mesma linha, Bozanic (2008) justifica juridicamente as razões para a não existência deste mercado. Para a autora, uma pessoa tem interesse segurável legítimo na sua própria vida e na vida de outros com quem tenha uma relação pessoal. Este princípio estaria sendo claramente violado ao se obter retorno com a morte de alguém, cujo nome é desconhecido pelo investidor e não há relação alguma de intimidade. Gasner (2008), em um argumento jurídico bastante similar, descreve os mecanismos de securitização dos seguros de vida e argumenta que, dentre diversos tipos de acordos possíveis, só há um tipo específico que, segundo as leis americanas, é ilegal. Trata-se da negociação de seguros de vida baseados em vidas de estranhos (STOLI).

Já Kohli (2006) argumenta que a legislação americana tem proporcionado uma estrutura adequada para proteger os segurados em uma transação de death bond, mesmo necessitando de maior regulamentação de preços, publicidade para o mercado e podendo haver eventuais conflitos de interesse. O autor vai além: havendo a devida atenção da legislação, o mercado secundário de vida pode tornar-se uma grande fonte de valor para os segurados.

De forma diversa do que ocorre em mercados mais desenvolvidos, a cultura do mercado segurador brasileiro é tratar o seguro de vida como um seguro temporário, de curto prazo (em geral, com duração de um ano), tratamento este que não permite acumulação de capital. Neste sentido, a criação do mercado secundário no Brasil é bastante prejudicada, apesar de não haver restrições legais para o acúmulo de reservas em seguro de vida. Além disso, a legislação brasileira, quando comparada à dos países supracitados, também é dúbia quanto à possibilidade da existência deste mercado. 0 Art. 760 do Código Civil de 2002 (que normatiza os contratos de seguros no Brasil) tem a seguinte redação:

"Art. 760. A apólice ou o bilhete de seguro serão nominativos, à ordem ou ao portador, e mencionarão os riscos assumidos, o início e o fim de sua validade, o limite da garantia e o prêmio devido, e, quando for o caso, o nome do segurado e o do beneficiário.

Parágrafo único. No seguro de pessoas, a apólice ou o bilhete não podem ser ao portador".

É possível concluir que a apólice não deve ser ao portador. No entanto, o Art. 791 do mesmo Código tem a seguinte redação:

"Art. 791. Se o segurado não renunciar à faculdade, ou se o seguro não tiver como causa declarada a garantia de alguma obrigação, é lícita a substituição do beneficiário, por ato entre vivos ou de última vontade.

Parágrafo único. O segurador, que não for cientificado oportunamente da substituição, desobrigar-se-á pagando o capital segurado ao antigo beneficiário".

O Art. 791 permite a troca de beneficiários de seguro de vida em qualquer instante, inclusive após a morte do segurado. Por meio da leitura conjunta dos Artigos 760 e 791, pode-se inferir que a legislação brasileira admite a existência deste mercado, desde que por meio de um acordo explícito entre o antigo segurado e o comprador da apólice e que, obrigatoriamente, a seguradora seja comunicada sobre tal acordo. A única barreira para a instituição do novo mercado no Brasil parece ser a ausência de tratamento do seguro de vida como constituição de acúmulo de reserva financeira de longo prazo.

Kohli (2006) argumenta que este mercado pode beneficiar os corretores de seguros de cinco maneiras. A primeira é por meio do recebimento de uma comissão paga pelos investidores para facilitar a negociação em mercado secundário. A segunda razão é que, em caso de seguro do tipo não quitado, os corretores podem receber comissões por renovações de apólices que teriam entrado em inadimplência e entrado em situações cujo valor do benefício teria sido reduzido. A terceira é a possibilidade de reinvestimento dos recursos advindos da operação, gerando com isso comissões. A quarta é que o corretor pode ganhar comissões por novos seguros de vida emitidos no mercado primário. Finalmente, 
o quinto modo é a participação dos corretores em alterações das cláusulas da apólice. Dadas essas possibilidades, o mercado pode vir a ser atrativo para os corretores: com o incentivo financeiro para recomendar operações que podem não ser as mais adequadas à situação de seus clientes, há necessidade de atenção adicional por parte dos legisladores.

Especificamente sobre o apreçamento dos títulos de seguro de vida, Menoncin (2009) apresenta uma forma fechada para a precificação de um death bond, quando adotada uma família de funções de sobrevivência, em tempo contínuo, chamada Gompertz-Makeham utilizando cálculo estocástico. Além disso, o autor apresenta a forma como o death bond deveria entrar no portfólio do agente comprador do título de vida do antigo segurado, de modo a maximizar a utilidade esperada do seu consumo intertemporal e sua riqueza final, quando o horizonte de tempo coincide com o instante de recebimento do benefício. Esta modelagem contribui para o apreçamento das taxas de retorno para os agentes no mercado, uma vez que o autor encontra formas fechadas de precificação quando são válidas as premissas supracitadas. No entanto, apesar da contribuição acadêmica, o enfoque do autor concentra-se nas demonstrações algébricas para a precificação do título, não concluindo sobre a viabilidade deste mercado.

A contribuição operacional esperada deste trabalho é dar um tratamento numérico e atuarial para a precificação dos death bonds, utilizando uma tábua de mortalidade amplamente utilizada pelo mercado segurador para a precificação primária. Com base nos resultados obtidos, faz-se uma extensão por meio da qual se tenta identificar os perfis de segurados mais interessantes do ponto de vista do investidor, bem como se apresenta uma discussão do impacto das possíveis falhas de mercado nos retornos financeiros esperados.

\section{O PRODUTO FINANCEIRO DEATH BOND}

Nesta seção será detalhado o funcionamento do mercado do título, bem como sua definição. Suponha que um segurado detentor de um seguro de vida, por quaisquer motivos, decide vender o direito de seus beneficiários receberem um montante estipulado por contrato; assim, o novo detentor deste direito, após pagar ao segurado um valor acordado, passa a ser o novo beneficiário do seguro, de forma a receber o benefício após a morte do segurado. Este título corresponde, portanto, a uma mudança de beneficiário do seguro por morte mediante pagamento antecipado em vida ao segurado, configurando-se como um derivativo de seguro de vida. Portanto, um death bond é um título lastreado em contratos de seguro de vida, no qual o recebimento do benefício por parte do portador (em geral, alguma instituição financeira) ocorre ao final do período de morte do segurado. A natureza aleatória deste título advém do fato de que apesar de o recebimento do benefício ser certo, uma vez que todos os segurados morrerão, há a incerteza quanto ao tempo a ser decorrido até a morte dos segurados.

Pode-se descrever o funcionamento do mercado de death bonds, conforme feito por Menoncin (2009) da seguinte maneira:

1. O segurado é o subscritor do seguro de vida. Quando este agente não possui mais interesse no seguro de vida, ele pode querer se desfazer de sua apólice;

2. O segurado contrata um corretor de seguros de vida (figura obrigatória em negociações de seguros em diversos países do mundo, inclusive no Brasil) que deverá encontrar um comprador para sua apólice. O comprador paga o valor presente líquido da reserva acumulada pelos pagamentos do segurado e recebe a apólice de seguro. Assim, o comprador deverá realizar os pagamentos restantes à seguradora para manter o valor inicialmente contratado, ou ajustar o seu valor presente. 0 comprador receberá da seguradora o benefício quando o segurado morrer. o segurado paga ao corretor de seguros uma comissão pré-estabelecida; 
3. Outro agente é o provedor do seguro de vida. Por meio dele, um fundo de investimentos ou um banco compra um conjunto de seguros de vida de uma ou mais seguradoras. Nesse caso, o fundo de hedge ou banco de investimentos receberá os prêmios do comprador e pagará o benefício final, e;

4. Na última etapa, após uma quantidade suficiente de apólices serem coletadas, tais apólices podem lastrear a emissão de um death bond. Assim, as apólices possuem o mesmo papel que os ativos em um título lastreado em ativos ou que as hipotecas em títulos hipotecários. O novo death bond é chamado de ativo transferido (pass through) se os prêmios recebidos pelo fundo de hedge são pagos diretamente aos investidores.

5. Este mecanismo de funcionamento pode ser resumido como exposto na Figura 1.

Figure 1: Fluxograma da emissão de um death bond

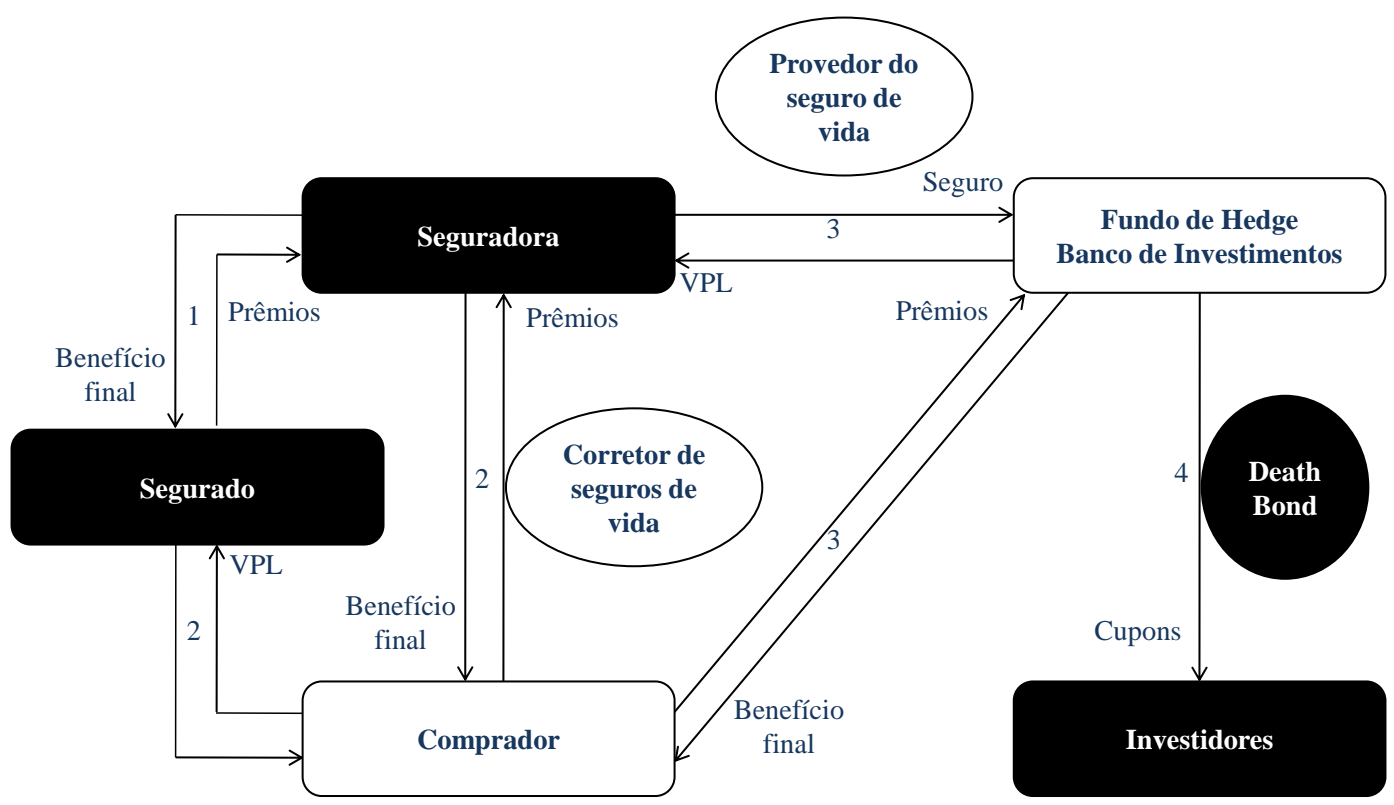

Fonte: Adaptado de Menoncin (2009).

Após a emissão de um título, é de interesse da instituição agrupar títulos de diversos indivíduos em uma carteira para pulverizar o risco de queda de retorno financeiro. Os perfis mais interessantes para a formação do portfólio serão identificados mais adiante.

\section{METODOLOGIA}

Como discutido anteriormente, a taxa de retorno de um título lastreado em um seguro de vida dependerá, basicamente, do montante financeiro que um indivíduo conseguiu acumular junto à entidade seguradora em regime financeiro de capitalização, cujo nome técnico é reserva de prêmios (RP) ou provisão matemática de benefícios a conceder (PMBaC). Trata-se de uma obrigação da seguradora 
em prover beneficios futuros ao segurado, mediante pagamento de um prêmio, seja ele fracionado ou único.

O cálculo do prêmio é determinado de modo a equivaler o montante a ser pago pelo segurado quando da contratação do produto ao valor presente esperado (VPE) do fluxo de pagamentos no futuro efetuado pela seguradora. O VPE depende de duas premissas fundamentais, que são a função de sobrevivência adotada, que fornece a probabilidade de um indivíduo sobreviver a um dado período de tempo, e a taxa de juros a incorrer no período de acumulação da $P M B a C$, de modo a representar a valorização financeira ao longo do tempo.

Por se tratar de um seguro de vida, faz-se a premissa de que o benefício será pago de uma só vez ao final do ano da morte do segurado ao seu dependente. Jordan (1991) argumenta que essa premissa é conveniente, uma vez que a probabilidade de morte pode ser obtida imediatamente a partir de uma tábua de mortalidade, sem que seja necessário adotar premissas adicionais sobre a taxa instantânea de mortalidade. Além disso, para o presente trabalho, serão calculados somente seguros de vida inteira (isto é, com cobertura por toda a vida do indivíduo, a partir da data de contratação), para garantir que existirá um pagamento certo ao beneficiário quando da morte do segurado.

Visando obter proteção financeira para si ou para sua família, é de interesse de determinado indivíduo adquirir seguro. Em se tratando de uma autoproteção financeira, o segurado poderia contratar uma renda para o período em que não mais for capaz de trabalhar, para a qual se dá o nome de previdência complementar. No caso de ele querer proteger financeiramente a sua família contra sua morte prematura, a opção oferecida pelo mercado é o chamado seguro de vida, em que um montante é pago aos beneficiários quando o segurado vier a falecer. Este seguro pode ser por um prazo determinado (temporário) ou cobrir toda a vida do segurado, sendo denominado seguro de vida inteira.

O enfoque do trabalho é na precificação secundária dos death bonds, que depende da contratação primária do seguro de vida, cuja forma de custeio dar-se-á sob o regime de capitalização, usualmente utilizado no mercado segurador. Existem diversas maneiras de um segurado pagar por este produto: seja de modo único ou parcelado. Há ainda a possibilidade de pagamento irregular, mas por não ser comum e de difícil modelagem, será desconsiderado neste trabalho.

\subsection{O modelo}

Esta subseção tem por objetivo principal apresentar o modelo a ser adotado para a realização das simulações. Também é apresentada de forma resumida a forma com que um seguro de vida inteira é precificado, como é feito pelas empresas seguradoras, empregando os conceitos de matemática atuarial. Mais detalhes sobre a teoria atuarial podem ser obtidas em Jordan (1991) e Bowers et al. (1997).

Define-se a taxa de desconto $\mathrm{v}$ como o fator redutor financeiro de fluxos futuros, dada a taxa de juros (i) a incorrer no período entre a contratação do seguro e a morte do segurado. O fator de desconto financeiro intertemporal, em tempo discreto, entre $t$ períodos é definido como $v=\frac{1}{(1+i)^{t}}$. Todavia, o fluxo de caixa do recebimento dos benefícios é probabilista, dada a incerteza da sobrevivência do segurado, sendo preciso ponderar o fluxo de pagamentos pela probabilidade de ocorrência do evento de interesse; neste caso, a morte do segurado.

Sejam $l_{x}$ e $d_{x}$ as quantidades de indivíduos vivos com idade $x$ (medida em anos) e de indivíduos falecidos antes de completarem $x+1$ anos, respectivamente, dadas por uma tábua de mortalidade qualquer. Pode-se determinar a probabilidade de um indivíduo morrer ou falecer na idade $x+t$, cuja notação é ${ }_{t} p_{x}$, a partir da interpretação clássica de probabilidade, isto é, pela razão entre os vivos com idade $x+t$ e com idade $x$. Por se tratar de uma probabilidade, o complementar ${ }_{t} q_{x}=1-_{t} p_{x}$ será a probabilidade de um indivíduo com idade $x$ vir a falecer entre $x$ e $x+t$.

o pagamento de uma só vez (sem parcelamentos) de um seguro de vida inteira no valor de uma unidade monetária $\left(A_{x}\right)$, também chamado de prêmio único puro (PUP), é definido como o valor presente da probabilidade de morte do indivíduo, e pode ser obtido utilizando a seguinte fórmula: 


$$
A_{x}=\sum_{t=0}^{\infty} v^{t+1}{ }_{t} q_{x}=\frac{1}{l_{x}} \sum_{t=0}^{\infty} v^{t+1} d_{x+t}
$$

Simplificando com algumas funções de comutação, ${ }^{4} D_{x}=v^{x} l_{x}, C_{x}=v^{x+1} d_{x}$ e $M_{x}=\sum_{t=0}^{\infty} C_{x+t}$, obtém-se o valor do seguro de vida inteira, uma unidade de capital paga ao beneficiário ao final do ano da morte do segurado trazida a valor presente:

$$
A_{x}=\sum_{t=0}^{\infty} v^{t+1}{ }_{t} q_{x}=\frac{1}{v^{x} l_{x}} \sum_{t=0}^{\infty} v^{x+t+1} d_{x+t}=\frac{1}{D_{x}} \sum_{t=0}^{\infty} C_{x+t}=\frac{M_{x}}{D_{x}}
$$

Como já apontado, o indivíduo poderia parcelar o pagamento do seguro em anuidades ou mensalidades. Uma opção é pagar por toda a vida ou somente por um período pré-determinado. No entanto, o indivíduo pode vir a falecer durante o período de pagamento (caso trivial quando a opção for pagar durante toda a vida) e, portanto, faz-se necessário, ponderar o fluxo de pagamentos pelas probabilidades de morte.

Para a determinação do valor de prêmio pago parcelado, é preciso antes determinar a fórmula da anuidade vitalícia contratada na idade $x\left(\ddot{a}_{x}\right)$. O trema denota que o prêmio será pago de modo antecipado, isto é, no início de cada período, para garantir que há recursos para efetuar o pagamento do seguro, caso a morte venha a ocorrer. Definindo-se a comutação $N_{x}=\sum_{t=0}^{\infty} D_{x+t}$, obtém-se:

$$
\ddot{a}_{x}=\sum_{t=0}^{\infty} v^{t}{ }_{t} p_{x}=\sum_{t=0}^{\infty} \frac{D_{x+1}}{D_{x}}=\frac{1}{D_{x}} \sum_{t=0}^{\infty} D_{x+1}=\frac{N_{x}}{D_{x}}
$$

Caso a opção de parcelamento seja de forma temporária, pode-se obter, a partir da Equação 3, a chamada anuidade temporária de $k$ anos, cuja notação é $\ddot{a}_{x \bar{k} \mid}$, fazendo a subtração entre $\ddot{a}_{x}$ e $\ddot{a}_{x+k}$.

Portanto, a quantia a ser paga anualmente, caso o segurado queira parcelar o valor do seguro de vida inteira, deve ser determinada pelo princípio da equivalência entre o valor presente esperado na idade $x$ da sequência de pagamentos de uma renda anual vitalícia e o valor esperado presente na idade $x$ do seguro contratado. Neste caso, o prêmio é chamado de prêmio puro nivelado anual (PNA), e, portanto:

$$
\ddot{a}_{x} P_{x}=A_{x} \Leftrightarrow P_{x}=\frac{A_{x}}{\ddot{a}_{x}}=\frac{M_{x}}{N_{x}}
$$

No entanto, o segurado pode optar por quitar o seguro de forma parcelada, mas em um período temporário de $k$ anos, cujo termo técnico é prêmio puro nivelado anual quitado em $k$ anos ( ${ } N A_{k}$ ), e cuja fórmula em comutação é dada por:

$$
{ }_{k} P_{x} \ddot{a}_{x}=A \Leftrightarrow{ }_{k} P_{x}=\frac{A_{x}}{\ddot{a}_{x: \bar{k} \mid}}=\frac{M_{x}}{\left(N_{x}-N_{x+k}\right)}
$$

O acúmulo de reservas depende do número de parcelas de pagamento de prêmios por parte do segurado à entidade seguradora. Naturalmente, a reserva de um indivíduo que pagou o PUP rende juros financeiros anualmente a partir da data de contratação. Para os casos de $P N A$ e $P N A_{k}$, existem duas formas de se avaliar a PMBaC: pelo método prospectivo, que é uma função descontada dos benefícios e prêmios a serem feitos no futuro, e pelo retrospectivo, ${ }^{5}$ que trata do reconhecimento dos valores acumulados no passado. Para o presente estudo, foi feita a opção pelo método prospectivo.

\footnotetext{
${ }^{4}$ Neste trabalho será adotada a notação da International Actuarial Notation (IAN) para as funções de comutação, cujo emprego de símbolos visa à simplificação do cálculo de prêmios de seguros e trata-se de um padrão na literatura atuarial. Mais detalhes em INSTITUTE OF ACTUARIES (1949).

${ }^{5}$ Jordan (1991) discute e apresenta ambos os métodos, além de mostrar que os resultados serão sempre iguais, sob manutenção das premissas iniciais.
} 
Para um seguro de vida inteira, parcelado conforme um PNA, contratado na idade $x$, a reserva acumulada até a idade $x+t,{ }_{t} V_{x}$, pode ser escrita como:

$$
{ }_{t} V_{x}=A_{x+t}-P_{x} \cdot \ddot{a}_{x+t}=\frac{M_{x+t}-P_{x} N_{x+t}}{D_{x+t}}
$$

Para o caso de seguro de vida inteira, cuja opção de parcelamento segue um $P N A_{k}$, a reserva acumulada até a idade $x+t$, cuja notação será ${ }_{t}^{k} V_{x}$, pode ser escrita como:

$$
{ }_{t}^{k} V_{x}=A_{x+t}-{ }_{k} P_{x} \cdot \ddot{a}_{x+t: \overline{k-t} \mid}=\frac{M_{x+t}-{ }_{k} P_{x}\left(N_{x+t}-N_{x+k}\right)}{D_{x+t}}
$$

Uma outra possibilidade de seguro é o chamado seguro quitado (paid-up insurance). Esta modalidade de seguro de vida permite que, para evitar uma eventual inadimplência por parte do segurado, seja possível renegociar o valor do benefício, a partir de uma reserva já acumulada. A fórmula de reavaliação da reserva de um seguro, denotada por ${ }_{t} W_{x}$, e cuja opção de pagamento foi PNA, é dada por:

$$
{ }_{t} W_{x}=\frac{{ }_{t} V_{x}}{A_{x+t}}=\frac{A_{x+t}-P_{x} . \ddot{a}_{x+t}}{A_{x+t}}=1-\frac{P_{x}}{P_{x+t}}
$$

Analogamente, pode-se obter a revisão do valor da cobertura para o caso de se ter a opção $P N A_{k}$ de parcelamento do prêmio:

$$
{ }_{t}^{k} W_{x}=\frac{{ }_{t}^{k} V_{x}}{A_{x+t}}=1-\frac{{ }_{k} P_{x}}{{ }_{k-t} P_{x+t}}
$$

\subsection{Rentabilidade do death bond}

A fim de analisar a taxa de retorno esperada por quem adquire o death bond, é preciso avaliar o montante a ser pago pelo comprador. É razoável supor que o comprador tenha o dispêndio de um montante proporcional à reserva acumulada pelo segurado e, em caso de morte do segurado, o benefício seria pago ao portador do death bond.

Desta maneira, define-se na Equação 10 , a taxa de retorno $\left(T R_{x, t, n}\right)$ do death bond, de forma análoga a Fabozzi (2000), descrita a seguir:

$$
T R_{x, t, n}=\frac{\left(\frac{K_{t} W_{x}}{(1+j)^{n}}\right)-{ }_{t} V_{x}}{{ }_{t} V_{x}}
$$

em que:

$x$ denota a idade em que o segurado contratou o seguro;

$t$ é o período decorrido entre a contratação do seguro até a negociação com a instituição que o adquire, isto é, o número de parcelas do PNA pagos pelo segurado à seguradora;

$n$ é o período decorrido entre a aquisição do seguro pela instituição até o recebimento do benefício, quando da morte do segurado, com a restrição $t \leq n$;

${ }_{t} V_{x}$ é a reserva acumulada pelo segurado (montante pago pelo título) entre as idades $x$ e $x+t$;

$j$ é a taxa de juros, denotando o custo de oportunidade da instituição que adquiriu o seguro;

$K_{. t} W_{x}$ é o valor do benefício a ser recebido pela instituição, quando da morte do segurado. 
Para avaliar o retorno esperado na transação do death bond por parte do comprador da apólice, é preciso avaliar uma taxa de retorno esperada $\left(T R E_{x, t, n}\right)$ no instante da negociação. Esta taxa de retorno deve ser ponderada pelas probabilidades de pagamento do benefício, que depende única e exclusivamente da probabilidade de morte do segurado, como evidencia a Equação 11.

em que:

$$
T R E_{x, t, n}=\frac{\sum_{n=t}^{\infty}\left\{q_{x+n} \Pi_{i=t}^{n-1}\left(p_{x+i}\right)\left[\frac{\left(\frac{K, t W_{x}}{(1+j)^{n}}\right)-{ }_{t} V_{x}}{{ }_{t} V_{x}}\right]\right\}}{\sum_{n=t}^{\infty}\left[q_{x+n} \Pi_{i=t}^{n-1}\left(p_{x+i}\right)\right]}
$$

$x$ denota a idade em que o segurado contratou o seguro;

$t$ é o período decorrido entre a contratação do seguro até a negociação com a instituição que o adquire, isto é, o número de parcelas do PNA pagos pelo segurado à seguradora;

$n$ é o período decorrido entre a aquisição do seguro pela instituição até o recebimento do benefício, quando da morte do segurado, com a restrição $t \leq n$;

${ }_{t} V_{x}$ é a reserva acumulada pelo segurado (montante pago pelo título) entre as idades $x$ e $x+t$;

$j$ é a taxa de juros, denotando o custo de oportunidade da instituição que adquiriu o seguro;

$K_{. t} W_{x}$ é o valor do benefício a ser recebido pela instituição, quando da morte do segurado;

$q_{n}$ é a probabilidade de o indivíduo morrer entre as idades $n$ e $n+1$, e;

$p_{i}$ é a probabilidade de o indivíduo sobreviver às idades $i$ e $i+1$. Se $n=t$, a expressão $\prod_{i=t}^{n-1}\left(p_{x+i}\right)$ não será calculada, dado que o segurado está vivo quando a transação do death bond é feita.

Os cálculos serão apresentados na próxima seção com o intuito de ilustrar a magnitude dos retornos que podem ser obtidos pelo investidor na negociação de um death bond.

\section{SIMULAÇÕES}

Nas subseções a seguir são apresentados os cálculos das taxas de retorno que servirão de subsídio para verificar a possibilidade da existência do mercado para os death bonds. O cálculo inicial é feito para um determinado perfil de segurado. Em seguida, será realizada uma análise de sensibilidade, com o intuito de identificar quais perfis de segurados podem ser mais interessantes do ponto de vista do investidor do death bond. Finalmente, é analisado como uma falha de mercado - a seleção adversa pode afetar as taxas de retorno do investidor.

Para a modelagem da mortalidade do segurado, será utilizada a tábua mais conservadora possível, a AT-2000 ${ }^{6}$ (masculina e feminina), em se tratando de sobrevivência. ${ }^{7}$ Este interesse na sobrevivência dá-se devido ao caráter indesejado, do ponto de vista do portador do death bond, de que o antigo segurado venha a falecer depois do que seria esperado para ele.

\footnotetext{
${ }^{6}$ Uma Annuity Table (AT) atuarial consiste em um método estruturado para determinar o valor presente de uma série de pagamentos futuros, no valor de uma unidade monetária, composta por um fator de desconto financeiro, ponderado pela probabilidade da ocorrência de morte. A tábua AT-2000, de uso padrão nos mercados seguradores do Brasil e dos EUA, foi calculada com base no padrão de mortalidade de 2000 da massa de indivíduos detentores de apólices de seguros de vida nos EUA.

${ }^{7}$ Chan et al. (2006) apresentam um comparativo entre diversas tábuas de mortalidade e verificam que a AT-2000 apresenta, para quase todas as idades, probabilidades de morte inferiores quando comparadas a outras comumente utilizadas no mercado, evidenciando que a expectativa de sobrevida da população é cada vez maior. Por este motivo, optou-se por empregar a tábua mais utilizada no mercado para a precificação e não fazer quaisquer simulações do impacto da alteração de tábuas por se tratar de um resultado esperado.
} 


\subsection{Cálculo da Taxa de Retorno para o investidor}

O cálculo da taxa de retorno $T R_{x, t, n}$ para o investidor é feito por meio da Equação 10. No processo de cálculo adotam-se as seguintes hipóteses: seja um homem que contratou na idade $x$ igual a 35 anos um seguro de vida inteira com valor de face $K$ igual a $\mathrm{R} \$ 100$ mil, cuja opção de pagamento foi por um PNA e estava adimplente até os 50 anos (portanto, $t=15$ ), quando decidiu negociar o seu seguro com uma instituição financeira. O benefício a ser recebido em caso de morte do segurado é o montante correspondente ao seguro quitado. Os valores supracitados foram utilizados para calcular a reserva acumulada $\left({ }_{15} V_{35}\right)$ até a data de negociação, a partir da Equação 6 e da revisão do montante a ser pago como benefício $\left(K_{15} W_{35}\right)$ advindo de um seguro quitado (calculado com o emprego da Equação 8), supondo que o portador não mais irá continuar o pagamento das anuidades do seguro de vida após a venda para o investidor. Os resultados são apresentados na Tabela 1.

Table 1: Precificação do seguro de vida para um indivíduo hipotético

\begin{tabular}{cc}
\hline Gênero (M/F) & $\mathrm{M}$ \\
Idade de contratação $(x$, em anos) & 35 \\
Parcelas anuais quitadas $(t$, em anos) & 15 \\
Idade Atual $(x+t$, em anos) & 50 \\
Taxa de Desconto Financeiro (ao ano) & $2 \%$ \\
Reserva Acumulada $\left({ }_{t} V_{x}\right)$ & $\mathrm{R} \$ 21.654,58$ \\
Cobertura $(K)$ & $\mathrm{R} \$ 100.000,00$ \\
Seguro quitado $\left(K_{. t} W_{x}\right)$ & $\mathrm{R} \$ 40.352,28$ \\
\hline
\end{tabular}

Fonte: Cálculos dos autores.

Os montantes apresentados na Tabela 1 mostram que o investidor estaria disposto a pagar $\mathrm{R} \$$ 21.654,58 (valor da reserva acumulada até a idade $x+t=50$ anos), por um seguro que pagará um benefício de R\$ 40.352,28 quando o antigo segurado vier a falecer. Em caso de morte do segurado no primeiro ano após a negociação do seu seguro de vida ( $n=1$, entre as idades 50 e 51 anos), calcula-se, por meio da Equação 10, uma $T R_{35,15,1}$ de $82,69 \%$. Ou seja, esta é a rentabilidade obtida pelo investidor se o segurado falecer no primeiro ano após a venda do seguro.

Uma vez computada a taxa de retorno do investidor para o primeiro ano, foram calculadas as taxas de retorno $\left(T R_{35,15, n}\right)$ do investidor para cada idade $(x+t+n$, com $n \geq 1)$ possível de morte do segurado. Estas são as taxas de retorno, por meio da Equação 10, para todos os possíveis valores de $n$, até que o indivíduo segurado atinja a idade limite da tábua AT-2000 adotada, que é de 115 anos. Os resultados estão evidenciados no Gráfico 1. Como é possível observar, a função de retorno da entidade, nova portadora do título, é monotonicamente decrescente, de tal forma que o instante de tempo em que o lucro estaria maximizado seria aquele imediatamente posterior à celebração do contrato. Este fato pode evidenciar o interesse dos compradores em adquirir os títulos de indivíduos com maior probabilidade de morte precoce, indicando a possibilidade de haver seleção adversa neste mercado.

Também é possível perceber, a partir do Gráfico 1, que há alteração no sinal do retorno do portador do título exatamente na idade em que é esperado o falecimento do antigo segurado. De acordo com as probabilidades da tábua AT-2000 Masculina, a expectativa de sobrevida de um homem de 50 anos de idade está entre 32 e 33 anos, como é possível observar no Gráfico 2, pela média da curva de mortalidade. Esta inversão demonstra uma característica intrínseca do título: dada a idade do segurado 
Gráfico 1 - Taxa de Retorno para o investidor, por idade de morte do segurado

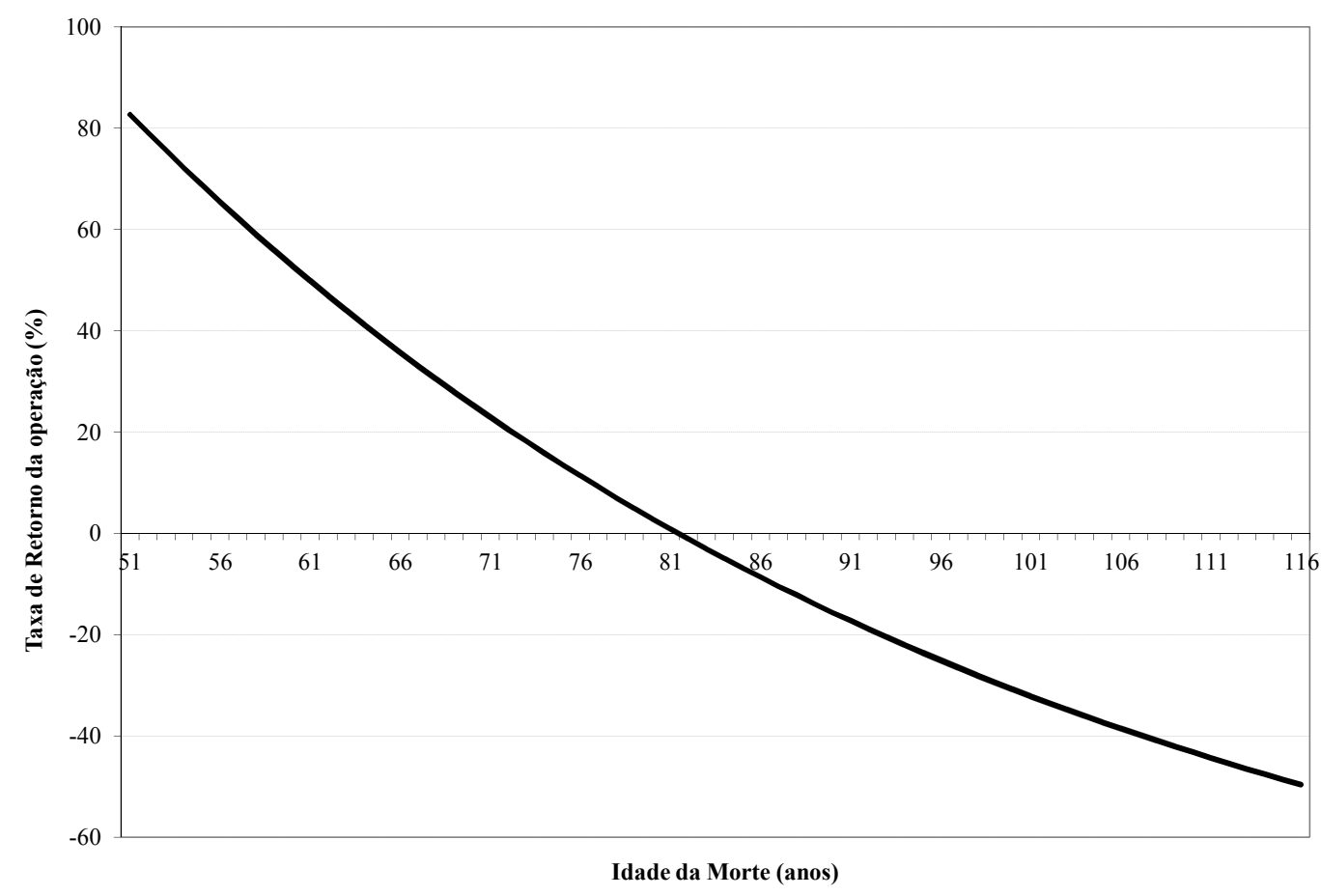

Fonte: Cálculos dos autores.

no instante da negociação, os retornos passam a ser negativos exatamente quando a idade esperada de sobrevida da pessoa é atingida.

Uma vez computados os retornos do investidor, em função da idade do segurado, é preciso avaliar as probabilidades de o segurado atingir cada uma das idades, de tal maneira que seja possível ponderar as rentabilidades de acordo com a sua sobrevida a fim de obter os retornos esperados pelos investidores, assim como a dispersão associada aos valores calculados.

A linha contínua do Gráfico 2 explicita as probabilidades de o segurado falecer entre as idades $x$ e $x+1$. A garantia de que o resultado está correto é evidenciado pela integral da curva pontilhada, que representa a distribuição da mortalidade acumulada, ser igual a 1, uma vez que todas as possibilidades de se falecer até o final da tábua estão cobertas. Ademais, a curva de probabilidades é uma distribuição levemente assimétrica à esquerda, favorecendo discretamente os maiores retornos associados às idades mais jovens.

Do ponto de vista do investidor, para avaliar a viabilidade deste mercado é necessário ter uma medida da expectativa de retorno do investimento feito no death bond, assim como a incerteza associada a essa métrica, que é representada pelo desvio-padrão. Observando a Equação 11, percebe-se que a taxa de retorno esperada pelo investidor $T R E_{x, t, n}$ é a média ponderada entre os retornos por idade e as respectivas probabilidades de mortalidade. Já o desvio-padrão, que mede o grau de risco associado à rentabilidade, é obtido pelo modo estatístico usual: a diferença entre o segundo momento e o quadrado do primeiro momento. 
Gráfico 2 - Probabilidade de se chegar vivo à idade $x$ e morrer entre as idades $x$ e $x+1$

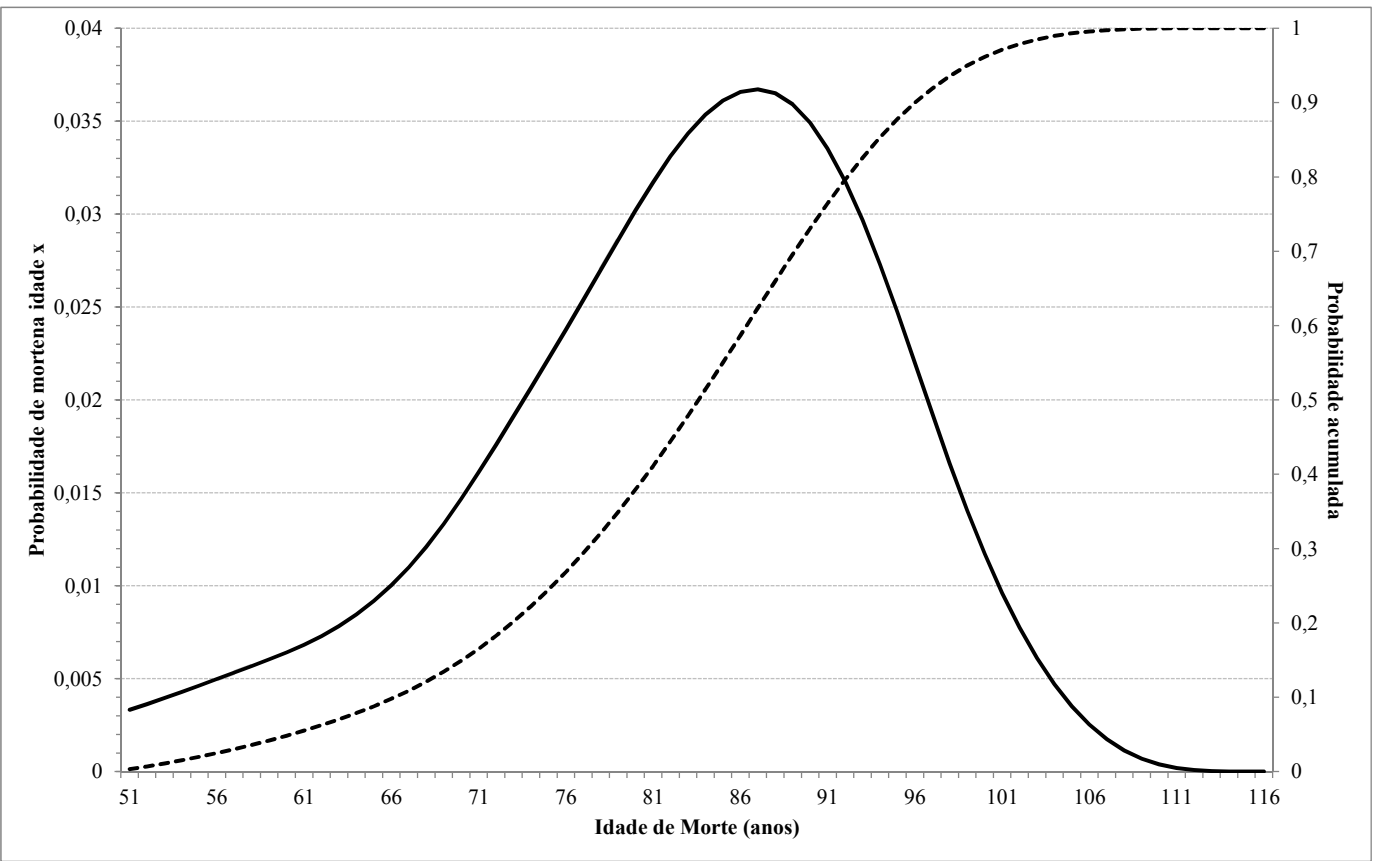

Fonte: Cálculos dos autores

Efetuando-se o cálculo da TRE e seu desvio-padrão, para o exemplo desta subseção, obtém-se $T R E_{35,15, n}=0,00001887 \%$, com um desvio-padrão de $24,2 \%$. Desta maneira, o investidor está diante de um mercado de expectativa de retorno aparentemente baixa, com um risco alto.

\subsection{Análise de sensibilidade da Taxa de Retorno para o investidor}

Uma vez executado o cálculo da Taxa de Retorno $T R_{x, t, n}$ para um indivíduo com um conjunto determinado de características, são feitas análises sobre o impacto de mudanças nos parâmetros. ${ }^{8}$ Analogamente aos cálculos efetuados na seção anterior, serão incorporadas mudanças no gênero do segurado (Masculino e Feminino), na idade de contratação do seguro de vida ( $x=0,20,40,60$ e 80 anos de idade), tendo pago um PNA durante $t=20$ anos, ${ }^{9}$ constante, e mudanças na idade de negociação secundária ( $x+t=20,40,60,80$ e 100 anos de idade, respectivamente). Os resultados são apresentados no Gráfico 2 . As curvas em questão mostram todas as taxas de retorno para cada uma das possíveis idades de morte do segurado, a partir do momento da negociação do seguro. Como exemplo, a curva de retornos do portador de um título oriundo de uma segurada mulher que vendeu seu seguro

\footnotetext{
${ }^{8}$ Optou-se por não simular variações na taxa de juros e nas tábuas de mortalidade devido a dois corolários derivados do Teorema de Lidstone, mostrando que aumentos na taxa de juros (ou na probabilidade de morte) produzem diminuição nas reservas acumuladas (e vice-versa) e, portanto, no montante pago pelo comprador do título. Esses aumentos alteram a magnitude dos retornos, mas não o formato geral da curva. A demonstração deste teorema pode ser encontrado em Jordan (1991, Cap. 5)

${ }^{9}$ Todas as simulações foram feitas com a reavaliação das reservas na data de negociação secundária, de tal forma que, independentemente de quantas foram as parcelas do PNA pagas, o retorno futuro do investidor mantém-se constante, dada a idade de negociação.
} 
aos 40 anos de idade, cuja contratação deu-se aos 20 anos, é dada pela cor verde escura. Analogamente, a curva de retornos para um segurado homem com as mesmas características é dada pela cor verde clara.

Gráfico 3 - Taxa de Retorno da instituição por idade de morte do segurado

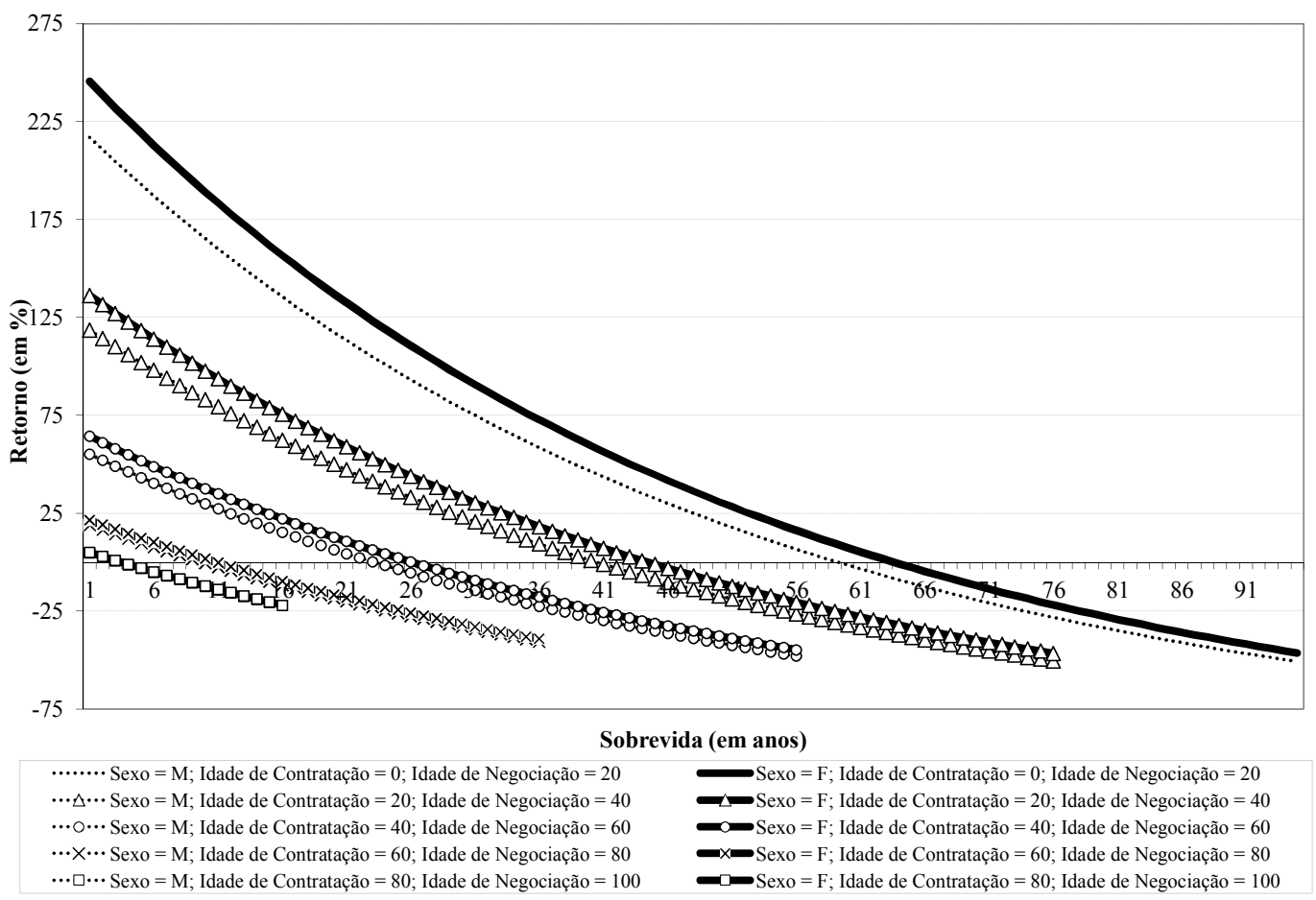

Fonte: Cálculos dos autores.

Observando o Gráfico 3, pode-se chegar a uma primeira conclusão. Há diferenças de retornos entre os gêneros, de forma que os retornos obtidos por uma apólice de uma segurada mulher são sempre mais altos, quando comparados aos retornos de um segurado homem em iguais condições de idades de contratação e negociação. Este fenômeno é explicado pela diferença entre os padrões de mortalidade, uma vez que mulheres têm expectativa de sobrevida maior e isto se reflete em probabilidades de morte mais baixas, fazendo com que os prêmios e, portanto, as reservas e montantes pagos pelo comprador do death bond, sejam menores. Apesar de o valor do benefício, quando da reavaliação, também ser menor, a redução relativa no montante do benefício é menos intensa que a redução da quantia a ser paga pela reserva, também devido à maior expectativa de sobrevida de uma mulher.

A mesma explicação deve ser usada para analisar a mudança de patamar das demais alterações. À medida que são adquiridos títulos de pessoas cada vez mais idosas, o retorno por idade diminui devido ao fato de que o montante a ser desembolsado pelo investidor ficará muito próximo ao valor a ser recebido. Outra razão é que a precificação primária onera mais os segurados idosos devido à iminência de sua morte.

Para o investidor poder fazer uma avaliação mais precisa da lucratividade deste título é necessário ter uma estimativa da taxa de retorno esperada, ponderando cada taxa de retorno de cada uma das curvas apresentadas no Gráfico 3 pela respectiva probabilidade da ocorrência de morte do segurado. Isto 
é feito com o emprego da Equação 11, por meio da qual se calcula $T R E_{x, t, n}$, utilizando procedimento análogo ao utilizado no exemplo da subseção anterior. São reportados também os desvios-padrão associados. Os resultados são apresentados na Tabela 2.

Table 2: $T R E_{x, 20, n}$ do death bond para os indivíduos simulados de diferentes idades de negociação $(x+20)$

\begin{tabular}{ccc}
\hline \multirow{2}{*}{ Idade de Negociação } & \multicolumn{2}{c}{ Gênero } \\
\cline { 2 - 3 } & $\mathrm{M}$ & $\mathrm{F}$ \\
\hline 20 & $0,000009 \%$ & $0,000032 \%$ \\
& $(32,99 \%)$ & $(30,46 \%)$ \\
40 & $0,000009 \%$ & $0,000033 \%$ \\
& $(27,11 \%)$ & $(25,63 \%)$ \\
60 & $0,000010 \%$ & $0,000035 \%$ \\
& $(20,21 \%)$ & $(20,01 \%)$ \\
80 & $0,000018 \%$ & $0,000051 \%$ \\
& $(11,76 \%)$ & $(12,04 \%)$ \\
100 & $0,000381 \%$ & $0,000803 \%$ \\
& $(4,47 \%)$ & $(4,71 \%)$ \\
\hline
\end{tabular}

Desvio-Padrão entre parênteses.

Fonte: Cálculos dos autores.

A primeira conclusão que pode ser extraída da Tabela 2 é que se trata de um investimento que apresenta sempre taxas positivas, apesar de extremamente reduzidas, indicando pouca atratividade neste produto, uma vez que boa parte dos títulos de renda fixa pode apresentar retornos bastante superiores aos encontrados. Uma explicação para este resultado é o fato de o investidor tarifar o título do segurado utilizando a mesma tábua de mortalidade utilizada pela seguradora. Desta maneira, o ganho do investidor dá-se pelo tempo de vida decorrido entre a contratação do seguro e a negociação, cuja probabilidade de morte do segurado era baixa. Este fato sinaliza que o investidor terá maiores retornos, quanto mais diferente for a expectativa de morte do segurado no momento da transação e o que foi previsto pela precificação primária.

Outra informação relevante é que, para ambos os gêneros, quanto mais idoso for o segurado, mais atrativa é a taxa de retorno para o investidor. Finalmente, quando se analisam as taxas de retorno de uma determinada idade de negociação, para títulos oriundos de vidas femininas, relativamente à de vidas masculinas, pode-se constatar que elas são sempre superiores a 2 , apesar de diminuírem à medida que a idade aumenta. Este fato é uma evidência que o investidor deverá ter maior interesse em seguradas mulheres do que em segurados homens.

Analisando a dispersão média associada a cada um dos retornos esperados apresentados, tem-se que a incerteza do retorno diminui conforme o aumento da idade da vida que deu origem ao título, independente do gênero. Quando se faz a comparação entre os gêneros, percebe-se que os títulos vinculados a vidas de mulheres são menos voláteis que aqueles vinculados a vidas masculinas até determinada idade (entre 60 e 80 anos), quando a situação se inverte. Tais resultados contradizem o que Gatzert (2010) e Doherty and Singer (2002) sugerem para títulos de vida de idosos: um death bond, tarifado segundo uma tábua padrão de mercado, não é um investimento que possui uma baixa medida de risco, uma vez que, apesar de os investidores certamente receberem o benefício, não se sabe 
quando isto irá ocorrer. Isto implica que, além de os investidores poderem incorrer em altos custos de oportunidade e terem retornos efetivos fortemente negativos, o retorno esperado pode ser considerado nulo, de tal forma que sua atratividade seja bastante reduzida.

Portanto, diante de uma população cuja mortalidade pode ser modelada com uma tábua conhecida, pode-se inferir que no caso de o investidor de um death bond querer maximizar o retorno esperado, ele buscaria títulos vinculados à mulheres e mais idosas. No entanto, caso procure retornos individuais maiores, deverá adquirir títulos de indivíduos do sexo feminino e jovens. Destaca-se, porém, que as taxas esperadas podem ser consideradas nulas a quase qualquer nível de confiança, indicando que não se trata de um produto financeiro de investimento interessante, uma vez que a precificação secundária reflete quase a mesma incerteza já mensurada pela precificação primária, diferindo apenas pelas probabilidades de morte até o período decorrido até a negociação do título.

Diante deste cenário, haveria condições mais propícias para que haja interesse de ambas as partes na transação do death bond? Isso será feito na Seção 6.

\section{SELEÇÃO ADVERSA: TENTANDO IDENTIFICAR O SEGURADO MAIS LUCRATIVO}

Na seção anterior foram identificados os perfis mais interessantes aos investidores, quando a probabilidade de morte é modelada por meio de alguma tábua de mortalidade padrão. No entanto, devido à assimetria de informações sobre o real estado de saúde (e, portanto, da probabilidade de morte) do segurado, o investidor que adquire o death bond pode estimar de forma incorreta a taxa de retorno esperada. Akerlof (1970) demonstrou de forma pioneira que se todos os seguradores têm informação imperfeita sobre o risco individual, o mercado de seguros poderia não existir e, no caso da existência, poderia não ser eficiente. Este fato justificaria, por exemplo, seguros de pessoas com idade mais avançadas terem os preços elevados na medida em que suas probabilidades de morte aumentam e, portanto, acabam sendo mais interessantes para o investidor do death bond. Logo, os investidores têm interesse em conhecer mais características do indivíduo do que apenas a sua idade.

De acordo com Varian (1992), a seleção adversa é uma falha de mercado em que o principal (instituição) possui menos informações que o agente (segurado), que pode causar a não existência de um equilíbrio, com uma mudança unilateral de comportamento. Como o investidor não é capaz de estimar precisamente a real probabilidade de o evento se materializar (neste caso, a morte do indivíduo), o título deverá ser tarifado pelo preço médio de todos os títulos. No entanto, segurados com probabilidade de morte mais elevada seriam aqueles que investidores estariam mais interessados em adquirir seus títulos, uma vez que poderiam receber maior retorno financeiro devido à morte prematura do segurado.

Considerando que pessoas com algumas doenças severas, como o câncer e a AIDS, por exemplo, têm probabilidade mais alta de vir a falecer, o investidor gostaria de identificá-las de indivíduos sadios, oferecendo preços distintos de modo a induzi-los a se distinguir dos demais. Este mecanismo de seleção por parte de investidores poderia fazer com que os indivíduos revelassem suas reais condições de saúde. Uma maneira hipotética de selecionar os segurados seria encontrá-los com suas doenças já diagnosticadas.

Não foram encontradas na literatura tábuas de mortalidade específicas para portadores de doenças graves. Dado este fato, recorreu-se à literatura médica a fim de se obter uma estimativa da expectativa de sobrevida de uma pessoa com uma doença grave. Para tanto, foram utilizadas as informações do projeto EUROCARE, que estudou a sobrevivência por câncer em países da Europa. Neste trabalho de Coleman et al. (2003) é feita uma análise detalhada de um estudo longitudinal com duração de 5 anos, avaliando 1,8 milhão de adultos e 24.000 crianças diagnosticados com câncer de diversos tipos, entre 1990 e 1994 e acompanhadas até 1999. As estimativas das probabilidades de morte que serão utilizadas para ponderar as taxas de retorno foram obtidas em Coleman et al. (2003) com os dados do projeto EUROCARE-3 e é apresentada na Tabela 3. 
Table 3: Distribuição categorizada de probabilidades de sobrevivência de tipos de câncer em homens e mulheres na Europa, diagnosticados entre 1990-1994 e acompanhados até 1999

\begin{tabular}{|c|c|c|c|c|}
\hline $\begin{array}{l}\text { Categorias de } \\
\text { probabilidade }\end{array}$ & $\begin{array}{l}\text { Ponto médio } \\
\text { da categoria }\end{array}$ & Homens & Mulheres & Total \\
\hline$\geq 80 \%$ & $90 \%$ & $2 \%$ & $5 \%$ & $4 \%$ \\
\hline $60-79 \%$ & $70 \%$ & $31 \%$ & $45 \%$ & $38 \%$ \\
\hline $40-59 \%$ & $50 \%$ & $25 \%$ & $23 \%$ & $24 \%$ \\
\hline $20-39 \%$ & $30 \%$ & $10 \%$ & $12 \%$ & $11 \%$ \\
\hline$<20 \%$ & $10 \%$ & $32 \%$ & $14 \%$ & $23 \%$ \\
\hline \multicolumn{2}{|c|}{ Total } & $100 \%$ & $100 \%$ & $100 \%$ \\
\hline \multicolumn{2}{|c|}{$\begin{array}{c}\text { Probabilidade média } \\
\text { de sobrevivência em } 5 \text { anos }\end{array}$} & $42,2 \%$ & $52,5 \%$ & $47,8 \%$ \\
\hline
\end{tabular}

Fonte: Adaptado de Coleman et al. (2003).

A Tabela 3 apresenta os tipos de câncer em homens e mulheres por categorias de probabilidade de sobrevivência em 5 anos, tempo de acompanhamento do estudo. Como exemplo, tem-se que $32 \%$ dos tipos de câncer que ocorreram em homens no período considerado tiveram probabilidade de sobrevivência dos indivíduos analisados inferior a $20 \%$. Para esta faixa de probabilidade de sobrevivência, $14 \%$ dos tipos de câncer ocorreram em mulheres. Este fato sugere que esta doença é menos fatal em mulheres do que em homens.

Baseado nas informações da Tabela 3, chega-se a uma estimativa da probabilidade de sobrevivência em 5 anos por gênero, ponderando tais probabilidades pelas frequências observadas nos gêneros. É possível inferir que, em geral, $42,2 \%$ dos homens e $52,5 \%$ das mulheres com câncer sobrevivem até 5 anos após o diagnóstico da doença. Com base nesta informação, foi efetuada uma interpolação linear para avaliar as probabilidades anuais de morte até $05^{\circ}$ ano da negociação e, efetuando uma extrapolação linear, até o período máximo de sobrevivência após o $5^{\circ}$ ano da negociação. Portanto, com esta interpolação, tem-se que a probabilidade anual de morte dos homens doentes de câncer é de $11,56 \%$, constante. Analogamente, a probabilidade anual de morte para as mulheres é de 9,50\%. Portanto, com as extrapolações lineares, um homem com câncer viveria no máximo mais 9 anos e uma mulher com câncer, 12 anos, a partir do diagnóstico.

Adotando-se a premissa de que a pessoa negocia o seguro de vida assim que descobre a doença (supondo que a finalidade da negociação do título é conseguir recursos para o tratamento), repete-se o procedimento da subseção 5.2, utilizando as estimativas interpoladas e extrapoladas das probabilidades de morte. Os resultados são apresentados na Tabela 4.

Analisando a Tabela 4, é possível perceber o efeito da seleção adversa, de modo que os retornos mais altos estão associados aos jovens doentes, o perfil mais atraente, nesta situação, para os investidores. Trata-se de um resultado coerente com as premissas adotadas, visto que as probabilidades de morte agravadas são justamente as associadas aos maiores retornos possíveis, dado que os retornos são monotonicamente decrescentes. Além disso, novamente as mulheres provêem retornos mais altos do que os homens. Coleman et al. (2003) justificam a maior probabilidade de expectativa de sobrevida da mulher devido ao fato de que os tipos de câncer mais comuns em homens (pulmão e estômago) têm altas taxas de morte e os mais comuns em mulheres (seios e útero) têm taxas mais elevadas de recuperação e sobrevivência. 
Table 4: $T R E_{x, 20, n}$ do death bond para os indivíduos simulados de diferentes idades de negociação $(x+20)$, utilizando probabilidades de morte para doentes de câncer

\begin{tabular}{ccc}
\hline \multirow{2}{*}{ Idade de Negociaçãoo } & \multicolumn{2}{c}{ Gênero } \\
\cline { 2 - 3 } & $\mathrm{M}$ & $\mathrm{F}$ \\
\hline \multirow{2}{*}{20} & $185,57 \%$ & $203,25 \%$ \\
& $(12,64 \%)$ & $(16,35 \%)$ \\
40 & $96,91 \%$ & $107,39 \%$ \\
& $(8,71 \%)$ & $(11,18 \%)$ \\
60 & $39,67 \%$ & $44,29 \%$ \\
& $(6,18 \%)$ & $(7,78 \%)$ \\
\multirow{2}{*}{80} & $7,00 \%$ & $6,66 \%$ \\
& $(4,73 \%)$ & $(5,75 \%)$ \\
\multirow{2}{*}{100} & $-5,65 \%$ & $-7,77 \%$ \\
& $(4,17 \%)$ & $(4,97 \%)$ \\
\hline \multirow{2}{*}{ Desvio-Padrão entre parênteses. } \\
Fonte: Cálculos dos autores.
\end{tabular}

As novas taxas de retornos esperadas apresentadas na Tabela 4 são mais altas e os respectivos desvios-padrão são sensivelmente inferiores em relação aos resultados reportados na Tabela 2 . À medida que se negocia com indivíduos que descobrem a doença mais tarde, tanto os retornos esperados quanto as variâncias associadas diminuem, porque já é esperado que esses indivíduos venham a falecer quando forem mais velhos. Este é o resultado que garante a atratividade desse mercado por parte dos investidores.

Um resultado particularmente interessante é a inversão do perfil de interesse entre 60 e 80 anos (mais precisamente entre 78 e 79 anos): embora já seja possível aceitar a hipótese (com 95\% de confiança e supondo normalidade) de que o retorno esperado pode ser considerado nulo, o retorno esperado para um homem idoso é mais alto do que para uma mulher idosa e também com menor incerteza associada. Esta situação está relacionada ao fato de as mulheres com câncer possuírem uma expectativa de sobrevida mais alta que o do homem, o que significa que o agravamento é aplicado por mais tempo e em retornos já menores, o que justifica tanto a diminuição da taxa de retorno esperada quanto o aumento da incerteza associada a este índice.

\section{CONSIDERAÇÕES FINAIS}

Neste trabalho buscou-se analisar a viabilidade deste mercado do mercado secundário de negociação de seguros de vida, por meio de simulações da precificação primária e secundária de seguro de vida, além de avaliar as possíveis falhas de mercado. Por meio de uma tábua de uma mortalidade padrão, avaliaram-se taxas de retorno esperadas pelo investidor e, considerando que se trata de um recebimento certo, porém com horizonte temporal incerto, os desvios-padrão associados às taxas. As primeiras comparações entre os principais fatores para a precificação, gênero e idade, evidenciam inicialmente que se trata de um investimento de pouca atratividade uma vez que apresenta taxas positivas, mas bastante reduzidas. Outra informação relevante é que, independente do gênero, quanto mais idoso for o segurado, maior é a taxa, bem como há maior interesse em vidas femininas do que masculinas. 
Avaliando uma situação em que é razoável avaliar um aumento da probabilidade de morte prematura, foi criado um cenário baseado na literatura médica. Os resultados apontam para a alta atratividade do produto por parte dos investidores, uma vez que o death bond traz taxas de retorno significativamente positivas e bastante altas, se comparadas com os resultado obtido por meio da tábua padrão do mercado utilizada no primeiro cenário. Portanto, há evidências de forte seleção adversa neste mercado.

Deve-se ter cautela ao se fazer inferências quanto à validade destes resultados para diferentes estágios da doença. O câncer é uma doença que quando diagnosticada em estágios tardios, pode apresentar menores probabilidades de cura. Para estudos futuros, pode-se pensar na análise para outros tipos de doença ou na modelagem mais refinada da curva de probabilidade de morte, além de outras possibilidades de seleção adversa.

\section{BIBLIOGRAPHY}

Akerlof, G. A. (1970). The market for 'lemons': Quality uncertainty and the market mechanism. Quarterly Journal of Economics, 84:488-500.

Bowers, N. L., Gerber, H. U., Hickman, J. C., Jones, D. A., \& Nesbitt, C. J. (1997). Actuarial Mathematics. The Society of Actuaries, 2nd. edition.

Bozanic, K. J. (2008). An investment to die for: From life insurance to death bonds, the evolution and legality of the life settlement industry. Penn State Law Review, 113:229-268.

Brasil (2002). Novo Código Civil Brasileiro. Lei $\mathrm{n}^{0}$ 10.406, de 10 de janeiro de 2002. Legislação Federal. Disponível em: http://www.planalto.gov.br/ccivil_03/LEIS/2002/L10406.htm. Acessado em setembro de 2010.

Chan, B. L., Silva, F. L., \& Martins, G. A. (2006). Tendência de aumento da expectativa de vida e a solvência das entidades abertas de previdência complementar. In $6^{\circ}$ Congresso USP de Controladoria e Contabilidade, São Paulo.

Coleman, M. P., Gatta, G., Verdecchia, A., Estève, J., Sant, M., Storm, H., Allemani, C., Ciccolallo, L., Santaquilani, M., Berrino, F., \& Eurocare Working Group (2003). Eurocare-3 summary: Cancer survival in Europe at the end of the 20th century. Annals of Oncology, 14:128-149.

Doherty, N. A. \& Singer, H. J. (2002). The benefits of a secondary market for life insurance policies. Working paper, Wharton Financial Institutions Center.

Fabozzi, F. J. (2000). Mercados, Análise e Estratégias de Bônus (Títulos de Renda Fixa). Quality Mark. Trad. da 3a. ed. americana.

Gasner, A. (2008). Your death: The royal flush of wall street's gamble. Hofstra Law Review, 37:599-663.

Gatzert, N. (2010). The secondary market for life insurance in the U.K., Germany, and the U.S.: Comparison and overview. Risk Management \& Insurance Review, 20:279-301.

INSTITUTE OF ACTUARIES (1949). International actuarial notation. Journal of the Institute of Actuaries, 75:121-129.

Jordan, C. W. (1991). Society of Actuaries' Textbook on Life Contingencies. The Society of Actuaries, 2nd. edition.

Kohli, S. (2006). Pricing death: Analyzing the secondary market for life insurance policies and its regulatory environment. Buffalo Law Review, 54:101-142. 
Quinn, S. (2008). The transformation of morals in markets: Death, benefits and the exchange of life insurance policies. American Journal of Sociology, 114:738-780.

Varian, H. R. (1992). Microeconomic Analysis. Norton, New York, NY, 3rd. edition. 